\title{
EXCLUSÃO DO ICMS-ST DA BASE DE CÁLCULO DO PIS E DA COFINS (RE 574706)
}

\author{
Ives Gandra da Silva Martins \\ Professor Emérito da Universidade Mackenzie em cuja \\ Faculdade de Direito foi Titular de Direito Constitucional \\ E-mail: ivesgandra@gandramartins.adv.br \\ Fátima Fernandes Rodrigues de Souza \\ Advogada em São Paulo e Professora do \\ Centro de Extensão Universitária \\ E-mail: fatima.souza@gandramartins.adv.br
}

Opinião Jurídica

\section{RESUMO}

O presente estudo trata de uma opinião legal sobre uma consulta referente ao cálculo correto do PIS/CONFINS sobre o faturamento. A franqueadora tem o interesse que os distribuidores passem a excluir o ICMS da base de cálculo do PIS/COFINS. Verifica-se, portanto, nesse estudo se é prudente ou não que os distribuidores passem a excluir o ICMS da base de cálculo das contribuições, com ou sem decisão judicial em ação individual que o autorize.

Palavras-chave: Constitucional. Tributário. Base de Cálculo PIS/COFINS.

\section{CONSULTA}

Relata-nos, a consulente, por seu eminente advogado, Dr. Ataíde Gil Guerreiro, dificuldades que estão sendo enfrentadas por seus associados para calcular corretamente o PIS/CONFINS sobre o faturamento, explicitando que:

O franqueador - no caso - obteve liminar que lhe permite excluir o ICMS incidente sobre os insumos utilizados no processo produtivo, da base de cálculo do PIS/COFINS.

Da mesma forma, alguns distribuidores estão pleiteando judicialmente a exclusão do valor correspondente ao ICMS da substituição tributária da base do cálculo do PIS/COFINS

A franqueadora como remunera os distribuidores sem considerar os impostos, tem interesse em que os distribuidores considerem a exclusão do ICMS substituição tributária no cálculo do PIS/COFINS, com o que manterá a margem dos distribuidores e o ganho com esta redução passará a aumentar o seu resultado financeiro. Pretende, portanto, que os distribuidores, a partir de $1^{\circ}$ de novembro, passem a excluir o ICMS substituição tributária da base de cálculo do PIS/COFINS, a pretexto de que estudaram detalhadamente a legislação e que esta nova sistemática poderá ser aplicada sem qualquer infração às leis em vigor. 
Para orientar os distribuidores, a consulente, vem consultá-lo sobre como agir, tendo em vista que :

1- Há distribuidores que recolhem normalmente o PIS/CONFINS sem considerar a exclusão do ICMS substituição tributária.

2- Há distribuidores que conseguiram liminar para excluir o ICMS substituição tributária do cálculo do PIS/COFINS, mas estão aguardando decisão final para aplicação deste novo cálculo.

3- Há distribuidores que conseguiram liminar para excluir o ICMS substituição tributária do cálculo do PIS/COFINS e já estão recolhendo com esta exclusão.

4- Há distribuidores que tentaram liminar para a exclusão do ICMS substituição tributária do cálculo do PIS/COFINS e não conseguiram.

\section{RESPOSTA}

Tendo em vista a urgência que nos foi comunicada pelo cliente, responderemos à consulta sob a forma de opinião legal.

O Judiciário vem reconhecendo que, no exercício de atividades sujeitas ao pagamento do ICMS sob o regime de substituição tributária, os contribuintes devem excluir o imposto estadual da base de cálculo do PIS e da COFINS, reconhecendo inclusive o direito de restituir ou compensar os valores recolhidos indevidamente nos últimos 5 anos, pelo fato de tal exclusão não ter sido feita oportunamente.

Tais decisões têm por base o que restou decidido pelo Supremo Tribunal Federal, no Recurso Extraordinário 574.706, julgado em 15 de março de 2017, quando ficou estabelecido que, por não caracterizar faturamento nem ingresso de receita - bases de cálculos do PIS e da COFINS -, o ICMS não deve compor as bases de cálculo das respectivas contribuições. Veja-se a ementa desse julgado, da relatoria da Ministra Carmen Lúcia:

- Recurso Extraordinário 574.706 Paraná: RECURSO EXTRAORDINÁRIO COM REPERCUSSÃO GERAL. EXCLUSÃO DO ICMAS NA BASE DE CÁLCULO DO PIS E COFINS. DEFINIÇÃO DE PATURAMENTO. APURAÇÃO ESCRITURAL DO ICMS E REGIME DE NÃO CUMULATIVIDADE. RECURSO PROVIDO.

1. Inviável a apuração do ICMS tomando-se cada medida ou serviço e a correspondente cadeia, adota-se o sistema de apuração contábil. O montante do ICMS a recolher é apurado mês a mês, considerando-se o total dos créditos decorrentes de aquisições e o total de débitos gerados nas saídas de mercadorias ou serviços: análise contábil ou escritural do ICMS

2. A análise jurídica do princípio da não cumulatividade aplicado ao ICMS há de atentar ao disposto no art. $155, \S 2^{\circ}$, inc I, da Constituição da República, cumprindo-se o princípio da não cumulatividade a cada operação.

3. O regime da não cumulatividade impõe concluir, conquanto se tenha a escrituração da parcela ainda a se compensar do ICMS, não se incluir todo ele na definição de faturamento aproveitado por este Supremo Tribunal Federal. O ICMS não compõe a base de calculo para a incidência do PIS e da COFINS.

4. Se o art. $3^{\circ}, \S 2^{\circ}$, inc I, in fine, da Lei 9718/1998 excluiu da base de cálculo daquelas contribuições sociais o ICMS transferido integralmente para os estados, deve ser enfatizado que não há como se excluir a transferência parcial decorrente do regime de não cumulatividade em determinado momento da dinâmica das operações.

5. Recurso provido para excluir o ICMS da base de cálculo da contribuição ao PIS e da COFINS. 
Em 24/04/2008, a Ministra Cármen Lúcia, reconheceu a repercussão geral da questão constitucional envolvida nesse recurso, que, àquele tempo, pendia de julgamento no Plenário do Supremo Tribunal Federal também no Recurso Extraordinário 240.785. A repercussão foi acolhida pelos demais Ministros e incluído o Tema sob nº 69.

A proclamação da existência de repercussão geral do tema constitucional suscitado em recurso extraordinário implica, a teor do que dispõe o art. 1035 do $\mathrm{CPC}$, o sobrestamento dos processos em que se discute a mesma matéria nas instâncias ordinárias, por determinação do Ministro Relator do STF.

No entanto, o art. 102, $\S 2^{\circ}$, da $\mathrm{CF}^{1}$ e, bem assim, o parágrafo único do art. 28 , da Lei 9868/99 somente atribuem efeitos erga omnes e vinculantes relativamente aos demais órgãos do Poder Judiciário e da Administração Pública direta e indireta da União, Estados, Distrito Federal e Municípios, às decisões definitivas de mérito proferidas em ações diretas de inconstitucionalidade (ADI) e ações diretas de constitucionalidade (ADC), remanescendo dúvidas sobre se tais efeitos também são produzidos pela decisão proferida em recurso extraordinário onde se reconheceu a repercussão geral.

Doutrinadores, como Kiyoshi Harada, ${ }^{2}$ dão resposta positiva a essa questão, observando que, "embora omissa tanto a Constituição, quanto a Lei 9868/99, não há dúvida de que a decisão proferida no Recurso Extraordinário com reconhecimento de repercussão geral vincula os demais órgãos do Judiciário, independentemente da existência ou não de Súmula Vinculante a respeito. A natureza vinculativa dessa decisão resulta implícita da própria técnica de seleção dos temas constitucionais que devem ser examinados pela Corte Suprema".

Outrossim, o Supremo Tribunal Federal, por suas duas Turmas, possui entendimento no sentido de que a existência de precedente firmado pelo Plenário da Corte autoriza o julgamento imediato de causas que versem sobre o mesmo tema, independentemente da publicação ou do trânsito em julgado do leading case.

Veja-se a ementa do ARE 781.214-AgR/SP, Relator o Ministro Dias Toffoli, Segunda Turma:

Agravo regimental no recurso extraordinário com agravo. Recurso contra decisão em que se aplicou o entendimento firmado no julgamento de mérito do RE n. 635.688/RS, submetido à sistemática da repercussão geral Trânsito em julgado. Ausência. Precedente do Plenário. Aplicação imediata. Possibilidade. Precedentes.

1. A existência de precedente firmado pelo Tribunal Pleno da Corte autoriza o julgamento imediato de causas que versem sobre a mesma matéria, independente de publicação ou do trânsito em julgado do paradigma.

2. Agravo regimental não provido.

E a ementa do ARE 930.647-AgR/PR, relator Ministro Roberto Barroso, Primeira Turma:

DIREITO ADMINISTRATIVO. AGRAVO REGIMENTALEM RECURSO EXTRAORDINÁRIO COM AGRAVO.LEGITIMIDADE. POLO PASSIVO. ASSISTÊNCIA À SAUDE. REPERCUSSÃO GERAL. INSURGÊNCIA VEICULADA CONTRA A APLICAÇÃO DA SISTEMÁTICA DA REPERCUSSÃO GERAL. POSSIBILIDADE DA APLICAÇÃO IMEDIATA DOS ENTENDIMENTOS

\footnotetext{
${ }^{1}$ Reza o $\S 2^{\circ}$ do art. 102 da CF; “ $§ 2^{\circ}$, As decisões definitivas de mérito, proferidas pelo Supremo Tribunal Federal, nas ações diretas de inconstitucionalidade e nas ações declaratórias de constitucionalidade, produzirão eficácia contra todos e efeito vinculante, relativamente aos demais órgãos do Poder judiciário e à administração pública direta e indireta, nas esferas federal, estadual e municipal."

2 (http://www.haradaadvogados.com.br/artigos -e-pareceres/artigos/)
} 
FIRMADOS PELO PLENÁRIO DO SUPREMO TRIBUNAL FEDERAL EM REPERCUSSÃO GERAL.

1. A existência de precedente firmado pelo Plenário desta Corte autoriza o julgamento imediato de causas que versem sobre o mesmo tema, independente da publicação ou do trânsito em julgado do paradigma. Precedentes.

2. Agravo regimental a que se nega provimento.

No mesmo sentido, ARE 673.256-AgR/RS Rel. Min Rosa Weber; AI 823.849-AgR/DF Rel. Min. Luiz Fux; ARE 686.607-ED/RS, Rel min Dias Toffoli; ARE 707.863-ED/RS Rel. Min Ricardo Lewandowski.

No caso da Consulta, não há notícia de que, em função do julgamento do Recurso Extraordinário 574.706, tenha havido o sobrestamento dos processos em que se discute a mesma matéria nas instâncias ordinárias, por determinação do Ministra Relatora do STF, possivelmente porque a União ofereceu, tempestivamente, embargos de declaração com efeitos infringentes.

Alegando que a retroatividade da decisão seria suscetível de gerar enorme controvérsia jurídica, por atingir o sistema tributário, alcançando outros tributos, projetar consequências nos preços relativos da economia; impor uma reforma tributária, e possibilitar vultosas repetições de indébito - a União pleiteia a modulação dos seus efeitos, sob o fundamento de que "teria restado definido no acórdão embargado que o debate sobre a matéria teria sido diferido para o momento da análise e apreciação desses embargos".

$\mathrm{Na}$ linha dessa argumentação, a Receita Federal emitiu, em 18 de outubro de 2018, a Solução de Consulta Interna n. 13, da Coordenação-Geral de Tributação (Cosit) determinando que deve ser usado no cálculo da exclusão, "o ICMS a recolher" e não "o ICMS total" destacado na nota fiscal, que tem sido adotado pela maioria dos contribuintes. Veja-se a ementa do ato:

Solução de Consulta Interna $\mathrm{n}^{\circ} 13$ - Cosit ASSUNTO: CONTRIBUIÇÃO PARA O PIS/PASEP EXCLUSÃO DO ICMS DA BASE DE CÁLCULO DA CONTRIBUIÇÃO EMENTA: “ASSUNTO: CONTRIBUIÇÃO PARA O PIS/PASEP EXCLUSÃO DO ICMS DA BASE DE CÁlCULO DA CONTRIBUIÇÃO. Para fins de cumprimento das decisões judiciais transitadas em julgado que versem sobre a exclusão do ICMS da base de cálculo da Contribuição para o PIS/Pasep, no regime cumulativo ou não cumulativo de apuração, devem ser observados os seguintes procedimentos:

a) o montante a ser excluído da base de cálculo mensal da contribuição é o valor mensal do ICMS a recolher, conforme o entendimento majoritário firmado no julgamento do Recurso Extraordinário n ${ }^{\circ}$ 574.706/PR, pelo Supremo Tribunal Federal;

b) considerando que na determinação da Contribuição para o PIS/Pasep do período a pessoa jurídica apura e escritura de forma segregada cada base de cálculo mensal, conforme o Código de Situação tributária (CST) previsto na legislação da contribuição, faz-se necessário que seja segregado o montante mensal do ICMS a recolher, para fins de se identificar a parcela do ICMS a se excluir em cada uma das bases de cálculo mensal da contribuição;

c) a referida segregação do ICMS mensal a recolher, para fins de exclusão do valor proporcional do ICMS, em cada uma das bases de cálculo da contribuição, será determinada com base na relação percentual existente entre a receita bruta referente a cada um dos tratamentos tributários (CST) da contribuição e a receita bruta total, auferidas em cada mês;

d) para fins de proceder ao levantamento dos valores de ICMS a recolher, apurados e escriturados pela pessoa jurídica, devem-se preferencialmente considerar os valores escriturados por esta, na escrituração fiscal digital do ICMS e do IPI (EFD-ICMS/IPI), transmitida mensalmente por cada um dos seus estabelecimentos, sujeitos à apuração do referido imposto; e 
e) no caso de a pessoa jurídica estar dispensada da escrituração do ICMS, na EFDICMS/IPI, em algum(uns) do(s) período(s) abrangidos pela decisão judicial com trânsito em julgado, poderá ela alternativamente comprovar os valores do ICMS a recolher, mês a mês, com base nas guias de recolhimento do referido imposto, atestando o seu recolhimento, ou em outros meios de demonstração dos valores de ICMS a recolher, definidos pelas Unidades da Federação com jurisdição em cada um dos seus estabelecimentos.

Dispositivos Legais: Lei $\mathrm{n}^{\circ} 9.715$, de 1998 , art. $2^{\circ}$; Lei ${ }^{\circ}$ 9.718, de 1998, arts. $2^{\circ}$ e $3^{\circ}$; Lei $\mathrm{n}^{\circ} 10.637$, de 2002 , arts. $1^{\circ}, 2^{\circ}$ e $8^{\circ}$; Decreto $n^{\circ}$ 6.022, de 2007; Instrução Normativa Secretaria da Receita Federal do Brasil no 1.009, de 2009; Instrução Normativa Secretaria da Receita Federal do Brasil no 1.252, de 2012; Convênio ICMS no 143, de 2006; Ato COTEPE/ICMS n ${ }^{\circ}$ 9, de 2008; Protocolo ICMS n ${ }^{\circ}$ 77, de 2008.

ASSUNTO: CONTRIBUIÇÃO PARA O FINANCIAMENTO DA SEGURIDADE SOCIAL - COFINS EXCLUSÃO DO ICMS DA BASE DE CÁLCULO DA CONTRIBUIÇÃO.

Para fins de cumprimento das decisões judiciais transitadas em julgado que versem sobre a exclusão do ICMS da base de cálculo da Cofins, no regime cumulativo ou não cumulativo de apuração, devem ser observados os seguintes procedimentos: a) o montante a ser excluído da base de cálculo mensal da contribuição é o valor mensal do ICMS a recolher, conforme o entendimento majoritário firmado no julgamento do Recurso Extraordinário $n^{\circ}$ 574.706/PR, pelo Supremo Tribunal Federal;

b) considerando que na determinação da Cofins do período a pessoa jurídica apura e escritura de forma segregada cada base de cálculo mensal, conforme o Código de Situação tributária (CST) previsto na legislação da contribuição, faz-se necessário que seja segregado o montante mensal do ICMS a recolher, para fins de se identificar a parcela do ICMS a se excluir em cada uma das bases de cálculo mensal da contribuição;

c) a referida segregação do ICMS mensal a recolher, para fins de exclusão do valor proporcional do ICMS, em cada uma das bases de cálculo da contribuição, será determinada com base na relação percentual existente entre a receita bruta referente a cada um dos tratamentos tributários (CST) da contribuição e a receita bruta total, auferidas em cada mês;

d) para fins de proceder ao levantamento dos valores de ICMS a recolher, apurados e escriturados pela pessoa jurídica, devem-se preferencialmente considerar os valores escriturados por esta, na escrituração fiscal digital do ICMS e do IPI (EFD-ICMS/IPI), transmitida mensalmente por cada um dos seus estabelecimentos, sujeitos à apuração do referido imposto; e

e) no caso de a pessoa jurídica estar dispensada da escrituração do ICMS, na EFDICMS/IPI, em algum(uns) do(s) período(s) abrangidos pela decisão judicial com trânsito em julgado, poderá ela alternativamente comprovar os valores do ICMS a recolher, mês a mês, com base nas guias de recolhimento do referido imposto, atestando o seu recolhimento, ou em outros meios de demonstração dos valores de ICMS a recolher, definidos pelas Unidades da Federação com jurisdição em cada um dos seus estabelecimentos.

Dispositivos Legais: Lei ${ }^{\circ} 9.718$, de 1998 , arts. $2^{\circ}$ e $3^{\circ}$; Lei $n^{\circ} 10.833$, de 2003 , arts. $1^{\circ}$, $2^{\circ}$ e 10; Decreto ${ }^{\circ}$ 6.022, de 2007; Instrução Normativa Secretaria da Receita Federal do Brasil $\mathrm{n}^{\circ}$ 1.009, de 2009; Instrução Normativa Secretaria da Receita Federal do Brasil $\mathrm{n}^{\circ}$ 1.252, de 2012; Convênio ICMS no 143, de 2006; Ato COTEPE/ICMS nº 9, de 2008; Protocolo ICMS n ${ }^{\circ} 77$, de 2008.

É bem de ver que o Supremo Tribunal Federal tem considerado cabível o pedido de modulação dos efeitos de decisão que reconhece a inconstitucionalidade de lei, sempre que haja a demonstração da excepcionalidade da situação ou a possibilidade de insegurança jurídica, como observou a Ministra Carmen Lúcia no RE 377.457.

Não se sabe, por ora, se a Corte vai considerar demonstrada essa excepcionalidade, no caso do RE 574.706, para o fim de modular os efeitos da decisão. 
Outrossim, o Tribunal tem considerado cabível a formulação do pedido de modulação dos efeitos da decisão por meio de embargos de declaração, como demonstra a decisão cuja ementa é transcrita abaixo, parcialmente, naquilo que aqui interessa:

EMBARGOS DE DECLARAÇÃO NA AÇÃO DIRETA DE INCONSTITUCIONALIDADE. ARTIGO 79 E 85 DA LEI COMP-LEMENTAR 64, DE 25 DE MARÇO DE 2002 DO ESTADO DE MINAS GERAIS (....) PRETENSÃO DE MODULAÇÃ̃O DE EFEITOS. PROCEDÊNCIA. EMBARGOS DE DECLARAÇÃO ACOLHIDOS PARCIALMENTE.

1.(...)

2. A modulação temporal das decisões em controle judicial de constitucionalidade decorre diretamente da Carta de 1988 ao consubstanciar instrumento voltado à acomodação otimizada entre o princípio da nulidade das leis inconstitucionais e outros valores constitucionais relevantes, notadamente a segurança jurídica e a proteção da confiança legítima, além de encontrar lastro também no plano infraconstitucional. (lei 9868/99, art. 27). Precedentes do STF; ADI no. 2.240; ADI n. 2.904; ADI 2907; ADI 3.022; ADI n. 3.315; ADI n. 3.316; ADI n. 3.430; ADI n.3489; ADI n. 3660; ADI n. 3682; ADI n. 3.682; ADI n. 3.689; ADI 3.819; ADI n. 4.009; ADI n. 4029.

3. In casu, a concessão de efeitos retroativos à decisão do STF implicaria o dever de devolução por parte do Estado de Minas Gerais de contribuições recolhidas por duradouro período de tempo (...)

4. Embargos de declaração acolhidos parcialmente para: (i)....; (ii) conferir efeitos prospectivos (eficácia ex nunc) à declaração de inconstitucionalidade proferida pelo Supremo Tribunal Federal no julgamento do mérito da presente ação direta, fixando como marco temporal de início de sua vigência a data da conclusão daquele julgamento (14 de abril de 2010) e reconhecendo a impossibilidade de repetição das contribuições recolhidas junto aos servidores públicos do Estado de Minas Gerais até a referida data.

A nosso ver, em matéria tributária, a modulação dos efeitos da decisão que reconhece a inconstitucionalidade da exigência de tributo só poderia militar a favor do contribuinte, quer porque, de outra forma, caracterizar-se-ia locupletamento ilícito do Estado valendo-se da própria torpeza (o Estado age contrariamente à Constituição editando lei inválida e depois se beneficia disso, apropriando-se do que foi recolhido indevidamente), quer porque quem tem que ser protegido contra a insegurança jurídica é o contribuinte, e não o próprio Estado, responsável pela edição de norma inconstitucional.

No entanto, nem sempre tem sido assim, como se viu no caso da decisão proferida no ERESP $n^{\circ}$ 462.446-MA, acerca da contagem do prazo prescricional, nos tributos sujeitos ao lançamento por homologação. O Tribunal assegurou o direito de repetir apenas aos contribuintes que haviam ingressado com ação para reaver o indébito até 9/6/2005. ${ }^{3}$

\footnotetext{
3 “TRIBUTÁRIO. EMBARGOS DE DIVERGÊNCIA. COMPENSAÇÃO. PIS. PRESCRIÇÃO. TERMO INICIAL DO PRAZO. LC N ${ }^{\circ}$ 118/2005. ART. $3^{\circ}$. NORMA DE CUNHO MODIFICADOR E NÃO MERAMENTE INTERPRETATIVA. INAPLICAÇÃO RETROATIVA. ENTENDIMENTO DA $1^{\mathrm{a}}$ SEÇÃO.

1. Está uniforme na $1^{a}$ Seção do STJ que, no caso de lançamento tributário por homologação e havendo silêncio do Fisco, o prazo decadencial só se inicia após decorridos cinco anos da ocorrência do fato gerador, acrescidos de mais um qüinqüênio, a partir da homologação tácita do lançamento. Estando o tributo em tela sujeito a lançamento por homologação, aplicam-se a decadência e a prescrição nos moldes acima delineados. (...) Aplica-se, assim, o prazo prescricional nos moldes em que pacificado pelo STJ, id est, a corrente dos cinco mais cinco.

2. A ação foi ajuizada em 22/03/1999. Valores recolhidos, a título de PIS, no período de 10/88 a 09/95. Não transcorreu, entre o prazo do recolhimento (contado a partir de 03/1989) e o do ingresso da ação em juízo, o prazo de 10 (dez) anos. Inexiste prescrição sem que tenha havido homologação expressa da Fazenda, atinente ao prazo de 10 (dez) anos $(5+$ 5), a partir de cada fato gerador da exação tributária, contados para trás, a partir do ajuizamento da ação. Precedentes desta Corte Superior.
} 
No caso do Recurso Extraordinário 574.706/P, a União sustenta que há dúvidas quanto ao momento a partir do qual a decisão produzirá efeitos. Não se sabe como o Supremo vai definir diversos aspectos do que restou decidido: se deve ser usado, no cálculo da exclusão, o ICMS a recolher ou o ICMS total destacado na nota fiscal (embora o voto da Ministra Cármen Lúcia tenha definido nesse sentido); se o Tribunal vai analisar a matéria à luz do princípio da nãocumulatividade (o que não teria sido feito no julgamento do mérito); se vai condicionar o direito ao ajuizamento de ação até a data do julgamento do mérito; ou se vai, eventualmente, analisar outros aspectos da decisão, que, alegadamente, não teriam ficado muito claros sobre a forma de apuração do montante a excluir e a repetir.

Assim, a nosso ver, até que tenha havido decisão definitiva nos embargos de declaração ofertados pela União, tornando intangível a decisão proferida no RE $n^{\circ}$ 574.706, o contribuinte deve agir com cautela, a) ingressando com a ação, se não o tiver feito; b) procedendo conforme decisão judicial que já tiver obtido; c) procedendo a provisão ou complementando-a, se a tiver feito, no caso de estar aproveitando o benefício ou se tiver baixado provisões anteriormente feitas, em face da decisão do Supremo Tribunal Federal.

Por tudo isso, embora consideremos razoável o entendimento sustentado pela franqueadora, na linha dos Arestos acima transcritos, não entendemos prudente que os distribuidores passem a excluir o ICMS da base de cálculo das contribuições, sem decisão judicial em ação individual que o autorize, tendo em vista que, a teor da Solução de Consulta acima referida, a Receita Federal certamente os autuará.

A possibilidade de a franqueadora, eventualmente, firmar termos com os distribuidores, assumindo a responsabilidade pelas consequências tributárias, em caso de autuações, não lhes oferecerá segurança prestante, tendo em vista que tais acordos não são oponíveis ao fisco, em face do art. 123, do CTN, que dispõe:

Art. 123 Salvo disposições em contrário, as convenções particulares, relativas à responsabilidade pelo pagamento de tributos, não podem ser opostas à Fazenda Pública, para modificar a definição legal do sujeito passivo das obrigações tributárias correspondentes.

É a nossa opinião, s.m.j.

3. Quanto à LC no 118/2005, a $1^{a}$ Seção deste Sodalício, no julgamento dos EREsp no 327043/DF, finalizado em 27/04/2005, posicionou-se, à unanimidade, contra a nova regra prevista no art. $3^{\circ}$ da referida Lei Complementar. Decidiu-se que a LC inovou no plano normativo, não se acatando a tese de que a mencionada norma teria natureza meramente interpretativa, restando limitada a sua incidência às hipóteses verificadas após a sua vigência, em obediência ao princípio da anterioridade tributária.

4. "O art. $3^{\circ}$ da LC $118 / 2005$, a pretexto de interpretar esses mesmos enunciados, conferiu-lhes, na verdade, um sentido e um alcance diferente daquele dado pelo Judiciário. Ainda que defensável a "interpretação" dada, não há como negar que a Lei inovou no plano normativo, pois retirou das disposições interpretadas um dos seus sentidos possíveis, justamente aquele tido como correto pelo STJ, intérprete e guardião da legislação federal. Tratando-se de preceito normativo modificativo, e não simplesmente interpretativo, o art. $3^{\circ}$ da LC 118/2005 só pode ter eficácia prospectiva, incidindo apenas sobre situações que venham a ocorrer a partir da sua vigência" (EREsp n ${ }^{\circ}$ 327043/DF, Min. Teori Albino Zavascki, voto-vista).

5. Embargos de divergência conhecidos e parcialmente providos para, com base na jurisprudência predominante da Corte, declarar a prescrição, apenas, das parcelas anteriores a 03/1989, concedendo as demais, nos termos do voto". (EREsp 462446/MA, Rel. E. Min. José Delgado, DJ 24.10.2005) 